\title{
Modeling 3D Rhône river plume using a higher order advection scheme
}

\section{Modelisation 3D du panache du Rhône basé sur un shéma d'advection d'ordre supérieur}

\author{
Sandrine Arnoux-Chiavassa, Vincent Rey, Philippe Fraunié * \\ Laboratoire de Sondages Electromagnétiques de l'Environnement Terrestre, UPRESA-CNRS 6017, \\ Université de Toulon et du Var, BP 132, 83957 La Garde cedex, France
}

\begin{abstract}
Effects of discretization scheme on the numerical modeling of 3D Rhône River plume dynamics are investigated. A higher order scheme of total variation diminishing (TVD) type is used to discretize advection terms of both momentum and scalar equations. It is shown that this scheme widely damps the numerical diffusion and improves the representation of the dynamical and density fronts bounding the flow. It enables to accurately investigate the effects of the turbulent diffusion, which was previously masked by the numerical one. Numerical results are also compared to in situ data for two situations related to different wind conditions. For the case without wind stress, associated to supercritical values of the Richardson number, optimized turbulent parameterization allows to recover the plume spreading and thickness, although local diffusion mechanisms are not precisely described. On the other hand, for the seaward wind case, associated to subcritical values of the Richardson number, numerical results and in situ data well agree on both the surface flow and the vertical density structure.
\end{abstract}

(C) 2003 Éditions scientifiques et médicales Elsevier SAS and Ifremer/CNRS/IRD. All rights reserved.

\section{Résumé}

L'influence des schémas de discrétisation d'un modèle numérique 3D sur la dynamique panacheuse du Rhône est étudiée. Des schémas de haute précision de type variation totale décroissante pour la discrétisation des équations de conservation de masse et de quantité de mouvement sont utilisés. La limitation de diffusion numérique caractéristique de ces schémas permet une meilleure représentation de la dynamique panacheuse, et plus particulièrement de ses fronts latéraux et de la stratification verticale. Les résultats numériques sont comparés à des données in situ pour différentes conditions de vent. Dans les cas sans vent, associés à des valeurs supercritiques du nombre de Richardson, la paramétrisation optimisée de la turbulence permet une bonne représentation de l'épaisseur et de l'extension du panache, tandis que les mécanismes locaux de diffusion ne sont pas décrits précisément. Par des conditions de vent de terre, associées à des valeurs sous-critiques du nombre de Richardson, les résultats numériques sont en bon accord avec les données in situ, pour l'écoulement de surface et la stratification verticale.

(C) 2003 Éditions scientifiques et médicales Elsevier SAS and Ifremer/CNRS/IRD. All rights reserved.

Keywords: Coastal oceanography; 3D numerical model; River plume; Stratified flows; Total variation diminishing schemes

Mots clés : Océanographie côtière ; Modèle numérique 3D ; Panache fluvial ; Écoulements stratifiés ; Schémas variation totale décroissante

\section{Introduction}

As river waters present the main supply of particulate and dissolved matter to continental shelves in the Region of Freshwater Influence (Rofi zone; Simpson, 1997), the study

* Corresponding author.

E-mail address: philippe.fraunie@1seet.univ-tln.fr (P. Fraunié). of surface river plumes they induce is of great interest for biogeochemical purposes.

River discharges onto shelves produce buoyant flows whose dynamics result from the complex non-linear interaction between the effects of unsteady wave and wind fields, rotation, buoyancy and turbulent mixing and also influence on the meso-scale circulation. Due to the large density gradi- 
ent between fresh and marine waters, these buoyant flows initially induce highly stratified situations, pertaining more or less downstream, depending on the mixing level caused by tidal and wind conditions. River plumes then present lateral and bottom fronts analyzed for example by Garvine (1977).

Extensive work has been carried out for the last 20 years on the topic of plume dynamics from a theoretical point of view, leading to a detailed knowledge of large estuarine plumes.

Chao and Boicourt (1986) studied the onset of an estuarine plume in a case without wind, using a 3D unsteady non-linear model. From a dynamical point of view, the flow can be divided into two parts: the near-field flow presents an anticyclonic vortex resulting in a downstream coastal current (far-field flow) after its impingement onto the coast. According to Stern et al. (1982), the buoyant coastal current dynamics reproduce the descriptions of a bore intrusion process. A cyclonic rotation marks the sharp transition from the nearfield flow to the far-field flow. By comparing their results with previous ones from linear studies (Beardsley and Hart, 1978; Ikeda, 1984), Chao and Boicourt showed that nonlinear effects are responsible for the transition sharpness.

Oey and Mellor (1993), focusing in the description of meso-scale features, used the Mellor and Yamada (1982) closure model to study the meandering of the coastal current. The instabilities were identified to be of period of order $5-10 \mathrm{~d}$.

Independently of these 3D studies, layer models focusing on the hyperbolic behavior of the flow have been developed (Garvine, 1982, 1984; O’Donnell, 1986; Garvine, 1987). Then, the thin freshwater layer was assumed to be vertically homogeneous, bounded downstream by a frontal zone but not to mix with the ambient marine water. Including rotation effects, Garvine (1987) found as Chao and Boicourt (1986) two main parts in the plume flow: the near-field flow which presents an inertial balance and a coastal current of width the order of the internal Rossby radius, result consistent with the work of Stern et al. (1982).

Because of the grid size, usual 3D studies did not resolve the frontal patterns of the plume boundaries. However, the first layer models did not take into account the mixing between both water masses. However, by including a parameterization of entrainment and mixing effects at the interface in a layer model, O'Donnell (1990) showed that the mixing processes have a strong influence on the internal flow structure. Davies and Xing (1999) investigated the sensitivity of plume dynamics to the vertical mixing.

Once features of a basic river plume were known, further studies on academic river plumes focused on the effects of external parameters like the bathymetry (Weaver and Hsieh, 1987; Chao, 1988a), an ambient transverse current (O'Donnell, 1990) or wind direction (Chao, 1988b; Xing and Davies, 1999). Tidal effects, leading to a mixing increase, have been introduced for example by Ruddick et al. (1995) or Kourafalou et al. (1996) on real-site studies.
The Rhône river site in the Mediterranean is characterized by a subsequent river discharge in a microtidal sea with a complex geometry where the tidal mixing effect, as observed for example in the Rhine plume (Ruddick, 1995) is no more observable.

In absence of wind, mixing between the Rhône brackish water and marine water is indeed very poor, as shown by the analysis of in situ measurements (Arnoux-Chiavassa et al., 1995; Broche et al., 1999). The plume remains then very thin and supercritical far downstream and is bounded by lateral haline fronts where the bulk of mixing between both water masses occurs.

Adding a wind stress, the mixing rate between both water masses is considerably increased but the lateral plume boundaries are still characterized by dynamic fronts.

For any wind condition, the representation of such dynamic and haline fronts and the parameterization of the mixing between the plume and marine waters represent a challenging effort for the Rhône plume modeling. As nonlinear terms are of importance in occurrence of fronts where advective processes predominate on diffusive ones, the advection scheme has to be carefully designed.

Numerical studies on the Rhône river plume have been recently carried out. Operational computations (Estournel et al., 1997; Marsaleix et al., 1998) focused on the unsteady plume extension due to realistic evoluting wind conditions with a coarse sigma coordinates discretization of the freshwater layer. In a previous study (Arnoux-Chiavassa et al., 1999) we computed typical quasi-steady climatic and hydrologic situations in order to evaluate sediment matter budgets in the coastal area.

Since these studies used a classical upwind advection scheme, artificial numerical diffusion dominated the exchange rates and did not allowed an accurate representation of the local exchanges in the vicinity of the fronts.

The aim of this paper is to improve the representation of the dynamical and haline fronts using a higher order advection scheme.

The physical and numerical model features are presented in Section 2 and Section 3 is devoted to the analysis of the Rhône river plume dynamics for different cases of meteorological forcing by means of numerical modeling and in situ measurements. Finally, conclusions are given in Section 4.

\section{The model formulation}

\subsection{Governing equations}

The 3D free-surface model is based on the primitive equations obtained by assuming that mass, momentum, salinity and temperature are conserved, assuming Boussinesq and hydrostatic approximations.

Within a Cartesian set $\left(O, x_{1}, x_{2}, x_{3}\right)$, where $x_{3}=0$ is the mean still water level and vertical axis $O x_{3}$ is directed downwards. Conservation equations write for finite volume discretization: 


$$
\begin{gathered}
\frac{\partial U_{j}}{\partial x_{j}}=0 \\
\frac{\partial U_{i}}{\partial t}+\frac{\partial\left(U_{i} U_{j}\right)}{\partial x_{j}}=\varepsilon_{i j 3} f U_{j}+g \frac{\partial \eta}{\partial x_{i}}-\frac{g}{\rho_{r}} \\
\int_{\eta}^{x_{3}} \frac{\partial \rho}{\partial x_{i}} d x_{3}^{\prime}-\frac{\partial\left(\overline{u_{i}^{\prime} u_{j}^{\prime}}\right)}{\partial x_{j}} \quad i=1,2 \\
\frac{\partial \phi}{\partial t}+\frac{\partial\left(\phi U_{j}\right)}{\partial x_{j}}=-\frac{\partial\left(\overline{u_{j}^{\prime} \phi^{\prime}}\right)}{\partial x_{j}}
\end{gathered}
$$

where $U_{i}, \eta, \rho, u_{i}^{\prime}, \phi, \phi^{\prime}$ denote respectively the mean velocity component along the axis $O x_{i}$, the free surface elevation, the density, the fluctuating velocity component along the axis $O x_{i}$, either the mean water salinity or temperature and either the fluctuating salinity or temperature. $\varepsilon, f, g, \rho_{\mathrm{r}}$ represent respectively the alternating unit tensor, the Coriolis parameter herein equal to $0.999 \times 10^{-4} \mathrm{~s}^{-1}$, the gravity and a reference density. The local density $\rho$ depends on the local salinity and temperature via a linearized state equation. The free surface elevation $\eta$ obeys the classical kinematic condition from depth integrated continuity equation:

$$
\frac{\partial \eta}{\partial t}+\frac{\partial \bar{F}_{1}}{\partial x_{1}}+\frac{\partial \bar{F}_{2}}{\partial x_{2}}=0
$$

where $\bar{F}_{i}=\int_{H}^{\eta} U_{i} d x_{3}$ and $H\left(x_{1}, x_{2}\right)$ is the water depth.

\subsection{Turbulent model}

The turbulent fluxes of velocity, salinity and temperature are given by:

$$
\begin{gathered}
-\overline{u_{i}^{\prime} u_{j}^{\prime}}=v_{t j} \frac{\partial U_{i}}{\partial x_{j}}+v_{t i} \frac{\partial U_{j}}{\partial x_{i}} \\
-\overline{u_{i}^{\prime} \phi^{\prime}}=D_{t j} \frac{\partial \phi}{\partial x_{j}}
\end{gathered}
$$

where $v_{\mathrm{t} i}$ and $D_{\mathrm{t} i}$ are the kinematic viscosity and salinity or temperature diffusivity coefficient along the axis $O x_{i}$. The turbulent Schmidt and Prandtl numbers are defined by the ratios of the kinematic viscosity coefficient to respectively the salinity and temperature diffusivity coefficient.

For the considered highly stratified turbulent flows in microtidal coastal sea, classical turbulent closure models including anisotropic corrections (Verdier-Bonnet et al., 1999) are not able to consider the rate between horizontal and vertical turbulent diffusion coefficients of order $10^{4}$ (Arnoux-Chiavassa et al., 1999).

Indeed, the horizontal diffusion coefficients can be evaluated as dependent on the horizontal grid size value expressed in meters, $\Delta_{\mathrm{h}}$, according to Tomidokoro (1984): $v_{t 1}=v_{t 2}=10^{-3} \Delta_{h}^{4 / 3}$ with horizontal Schmidt and Prandtl numbers of order 1 .

The vertical turbulent coefficients have to account for the stratification effects and the wind induced turbulence.

For modeling river plume flows, most of the previous studies used an equation for the turbulent kinetic energy $k$ in the saline outer flow (Oey and Mellor, 1993; Ruddick et al.,
1995; Luyten et al., 1996; Estournel et al., 1997; Marsaleix et al., 1998).

Because of the high stratification encountered in the Rhône plume, and following Kao et al. (1977), Wang (1984) or Brooks (1994), we have chosen an algebraic Munk and Anderson (1948) type model:

$$
\begin{aligned}
v_{\mathrm{t} 3} & =\frac{v_{\mathrm{t}_{0}}}{(1+10 R i)^{1 / 2}}+v_{\text {min }} \\
D_{\mathrm{t} 3} & =\frac{D_{\mathrm{tv}_{0}}}{\left(1+\frac{10}{3} R i\right)^{3 / 2}}+D_{\text {min }}
\end{aligned}
$$

where $v_{\mathrm{t} v 0}$ and $D_{\mathrm{t} v 0}$ represent the values for a neutral stratification state. Turbulent viscosity and diffusivity coefficients depend then on stratification and shear stress via the local gradient Richardson number

$$
R i=\frac{g \frac{\partial \rho}{\partial x_{3}}}{\rho_{r}\left[\left(\frac{\partial U_{1}}{\partial x_{3}}\right)^{2}+\left(\frac{\partial U_{2}}{\partial x_{3}}\right)^{2}\right]}=\frac{N^{2}}{\left(\frac{\partial U_{h}}{\partial x_{3}}\right)^{2}}
$$

and are bounded by values equal to the molecular diffusion coefficients $\left(v_{\min }\right.$ and $\left.D_{\min }\right)$. According to other studies (Wang, 1984; Chao and Boicourt, 1986), turbulent coefficients for the neutral stratification state range from $10^{-4}$ to $10^{-3} \mathrm{~m}^{2} \mathrm{~s}^{-1}$. The turbulent diffusion coefficient for salinity at the neutral state $D_{\mathrm{t} v 0}$ is fixed through the turbulent Schmidt number for the neutral state $S c_{0}$. Launder (1978) recommended a value of 0.7 , Rodi (1984) proposed a value ranging from 0.5 to 1 and the parameterization of Galperin et al. (1988) led to a value of approximately 0.8 . We chose then to vary the values from 0.6 to 1 , depending on the wind conditions and by calibration from experimental data.

In fact, it is well known from laboratory experiments (Linden, 1980) and observations (Ivey and Imberger, 1991) that for supercritical values of the Richardson number, the turbulent structure of stratified layers is strongly modified. Indeed, when the Brunt Väisälä time scale N in Eq. (8)) is faster than the time scale of the vertical shear of horizontal motion $\left(\frac{\partial U_{h}}{\partial x_{3}}\right.$ in Eq. (8)), the stratification rearranges an initially linear stratification in a quasi-homogeneous layer. Such behavior clearly occurs in the Rhône river plume by the layer models.

\subsection{Boundary conditions}

The inlet flow rate at the river mouth is fixed through a velocity profile.

At the solid boundaries, impermeability and no-slip conditions are applied on the velocity field, and zero flux conditions are applied on salinity and temperature.

At the sea surface, the wind shear is expressed by a quadratic law. The drag coefficient introduced in this law may either be constant or vary with the fetch according to Vickers and Mahrt (1997). Zero flux conditions are applied on salinity and temperature. 
At the open sea boundaries, and because of the quasilinear coastline, simple Dirichlet or Neumann conditions are used for the velocity field, depending on the occurrence of an offshore current, associated to a radiative condition for the free-surface elevation, which depends on the depthintegrated normal velocity according to Wurtele et al. (1971).

\subsection{Numerical resolution}

The governing equations are solved using a Finite Volume method (Verdier-Bonnet et al., 1999) on a variable staggered Cartesian mesh of Arakawa C type (Arakawa and Lamb, 1977).

A variable Cartesian mesh has been preferred to a $\varsigma$-layering method for a refined discretization of the thin freshwater layer and to avoid numerical instability.

Horizontal resolution is of $1 \mathrm{~km}$ and the vertical grid size varies from $\Delta x_{3}=50 \mathrm{~cm}$ in the surface layer to $\Delta x_{3}=10 \mathrm{~m}$ in the deep water.

Time discretization is achieved through an explicit Euler time marching scheme. Except the advection terms, all the terms are discretized in space by a centered scheme of order 2 .

Concerning the non-linear advection terms, the classical upwind method of order 1 introduces artificial numerical diffusion, that unable to correctly reproduce the sharp momentum and haline fronts and sometimes results even in a qualitative misrepresentation of the flow (Leonard and Drummond, 1995).

Piecewise parabolic methods have been employed for the advection schemes of scalar fields in coastal stratified flows (Ruddick, 1995; James, 1996; Lin and Falconer, 1996; Ouahsine and Smaoui, 1999). Due to the strong velocity gradients encountered in weakly mixed microtidal environment, higher order advection schemes have been considered here also for momentum equations.

The quadratic upstream interpolation for convective kinematics-Quick scheme (Leonard, 1979) uses a thirdorder upwind approximation and introduces a limited numerical diffusion. However, because of its quadratic interpolation, it induces undershoots and overshoots in regions of high gradient variations, themselves generating spurious wiggles which can be avoided by use of monotonicity preserving schemes (Total Variation Diminishing type, Sweby, 1984; Roe, 1985).

Bounded Quick schemes (Gaskell and Lau, 1988; Leonard and Mokhtari, 1990; Varonos and Bergeles, 1998), which are easily implemented, allow to keep a high order accuracy except in the vicinity of the fronts.

In this work, we used the sharp and monotonic algorithm for realistic transport (Smart) scheme (Gaskell and Lau, 1988) for discretizing the advection terms in both scalar and momentum equations. The detailed discretization procedures are presented in Arnoux-Chiavassa (1998).

Stability conditions on the time step due to the advection scheme are then those given by Leonard (1979).

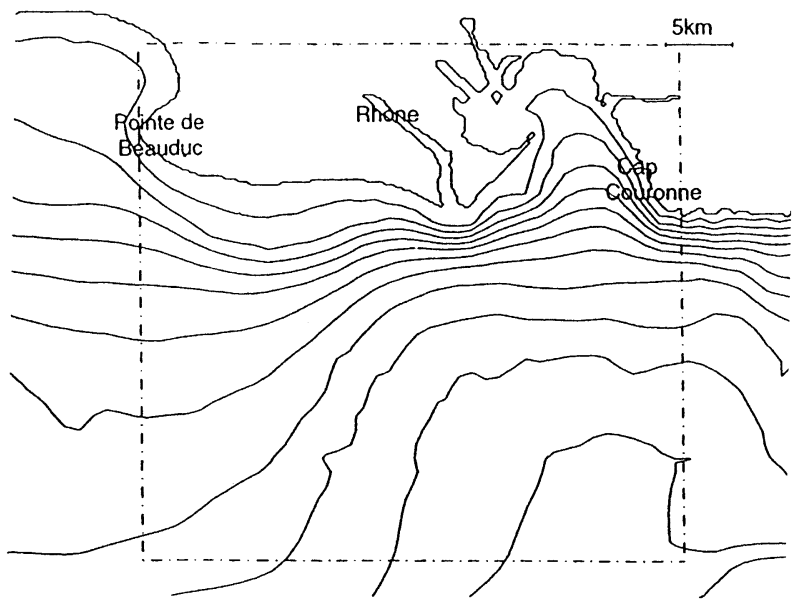

Fig. 1. Bathymetry of the region off the Rhône River mouth. Isobath lines are plotted every $10 \mathrm{~m}$ from 10 to $120 \mathrm{~m}$. Limits of the computational domain are plotted with dashed lines. The map is oriented with respect to the north direction.

Computational domain (Fig. 1) extends $40 \mathrm{~km}$ offshore, the order of the Rossby radius, to account for upwelling effects. Forcing by large-scale circulation (the LiguroProvençal current in the Mediterranean basin) is introduced through the open sea boundary conditions. In the cases herein considered of Northern wind or without wind its influence was found of secondary order.

All simulations presented here exceed $45 \mathrm{~h}$, which is the spin up time in the given computational domain.

\section{Modeling the Rhône river plume dynamics}

Numerical results for the Rhône river plume dynamics are compared to in situ observations for two characteristic situations with significant steady river flow conditions encountered during a field campaign (Arnoux-Chiavassa et al., 1995; Broche et al., 1999): the first one without any wind stress and the second one for strong seaward wind conditions (e.g. Fig. 10).

Sea surface current maps with an integration depth of about $25 \mathrm{~cm}$ were available every $30 \mathrm{~min}$ from two VHF radars measurements analysis. The area of measurements extended from the river mouth to about $20 \mathrm{~km}$ around the river mouth. The plume lateral fronts are clearly observable by velocity discontinuities.

Data including surface trajectories from drifted buoys, suspended sediment sampling and vertical profiles using a CTD probe were collected during the first and the last weeks of the field campaign. Data concerning wind and Rhône flow rate were registered on the whole period and three satellite images were obtained. Unfortunately, no data on the LiguroProvençal Current has been successfully registered. Nevertheless, this along-shore current is assumed not to flow in the near coastal zone in this region and then to have a minor influence on the Rhône plume (Millot, 1990), except for eastern winds. 


\subsection{The Rhône river plume dynamics}

The Rhône river outflows into the Northwestern Mediterranean onto the continental shelf of the Gulf of Lions. The complex bathymetry exhibits a steep slope from the river mouth (Fig. 1). The mean annual flow rate of the Rhône river is about of $1700 \mathrm{~m}^{3} \mathrm{~s}^{-1}$, which is close to the critical value determining the formation or breakup of the salt wedge estimated by Ibanez et al. (1997) at about $1500 \mathrm{~m}^{3} \mathrm{~s}^{-1}$.

River discharges modeled in this paper are characteristic of the fall period and range from 2000 to $3000 \mathrm{~m}^{3} \mathrm{~s}^{-1}$. No salt wedge is then allowed in our numerical runs. At the initial state, the sea is considered as homogeneous and at rest. The discharge starts impulsively and is modeled as an inflow of fresh water of zero salinity.

\subsection{The river flow induced circulation}

In this section, we will first study the general Rhône plume flow without any wind stress and will focus in the improvements brought by a higher order advection scheme by reference to the upwind scheme (Arnoux-Chiavassa et al., 1999).

Fig. 2a,b depict a horizontal view of the surface dynamic and salinity fields obtained using the Smart scheme for a river discharge of $2500 \mathrm{~m}^{3} \mathrm{~s}^{-1}$ and the following turbulent coefficients: $v_{\mathrm{t} v 0}=6 \times 10^{-4} \mathrm{~m}^{2} \mathrm{~s}^{-1}, D_{\mathrm{t} v 0}=10^{-3} \mathrm{~m}^{2} \mathrm{~s}^{-1}, S c_{0}=0.6$. Once released at the mouth following a direction close to the south-east, the fresh water spreads radially onto the shelf. The plume flow undergoes simultaneously an important speed-down caused by both the fresh water spreading and the vertical shear.

At a downstream distance of order of the internal Rossby radius, the flow turns right driven by the Coriolis force, then forming the anticyclonic vortex previously observed in numerical studies (see e.g. Chao and Boicourt, 1986 or Garvine, 1987). This vortex is associated to a sea surface bulge caused by the upwelling motion occurring inside and beneath the plume. On the other hand, downwellings occur at the bulge lateral boundaries. When impinging downstream into the coast, the flow turns in cyclonic sense in a quite sharp way and forms a coastal current. The speed-up observed in this transition region may be related to the initiation of a bore intrusion process. According to Chao's classification (Chao, 1988a) based on the ratio of the offshore bulge extension to the coastal current width, this plume is clearly supercritical.

Visualization of the salinity field (Fig. 2b) shows that a haline sharp gradient laterally bounds the river plume. In the central part of the plume, fresh water progressively mixes with sea water when flowing, but this mixing remains quite weak. When using the classical upwind scheme of order 1 for discretizing the advection terms, haline plume fronts are not evidenced anymore and mixing in the central part is faster (Fig. 3), due to the numerical diffusion.

This numerical behavior is confirmed by the vertical density structures (Fig. 4) where the higher order scheme provides a sharper halocline. (a)

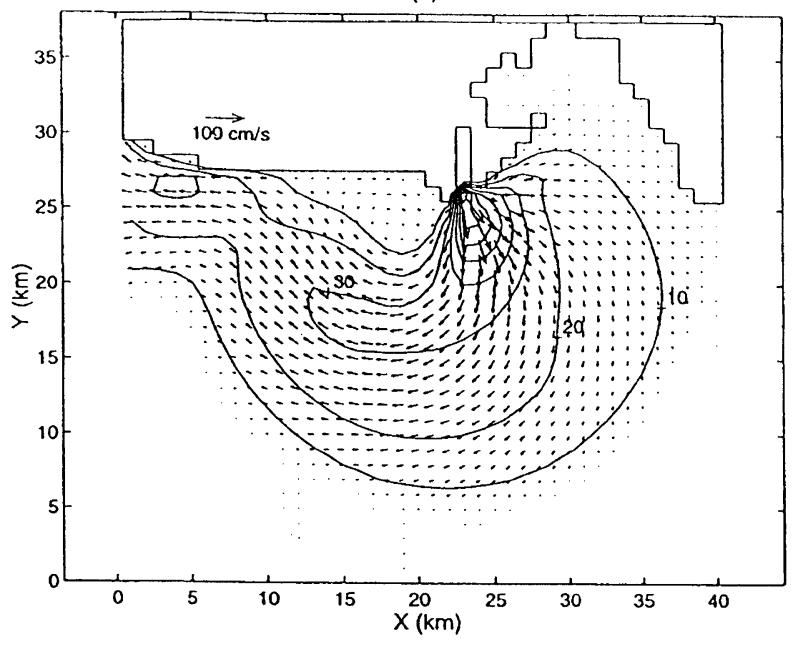

(b)

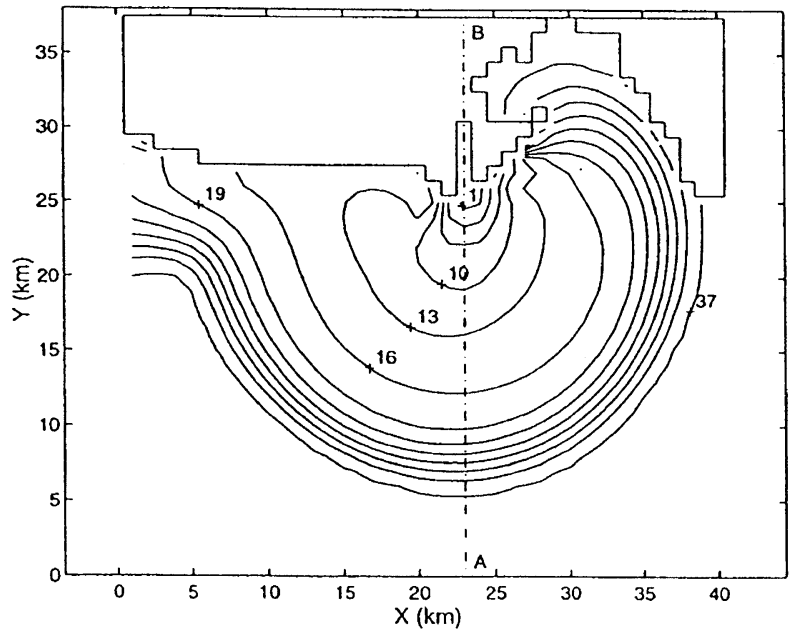

Fig. 2. Surface maps of the (a) dynamic and (b) salinity fields obtained using the SMART scheme and the following turbulent coefficients: $v_{\mathrm{t} v 0}=6 \times 10^{-4}$ $\mathrm{m}^{2} \mathrm{~s}^{-1}, D_{\mathrm{t} v 0}=10^{-3} \mathrm{~m}^{2} \mathrm{~s}^{-1}, S c_{0}=0.6$. Velocity and salinity isolines are plotted respectively every $10 \mathrm{~cm} \mathrm{~s}^{-1}$ and 3 psu.

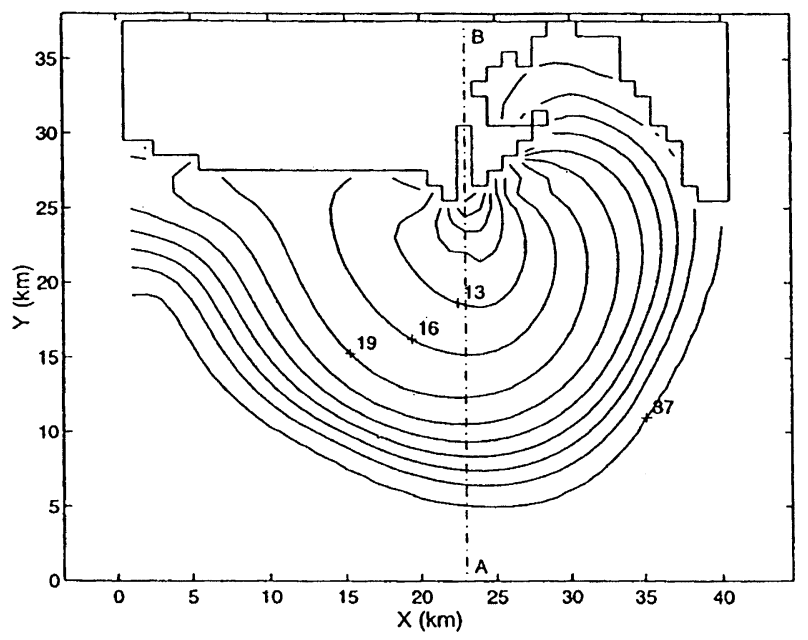

Fig. 3. As Fig. 2b except for the advection scheme which is upwind. 

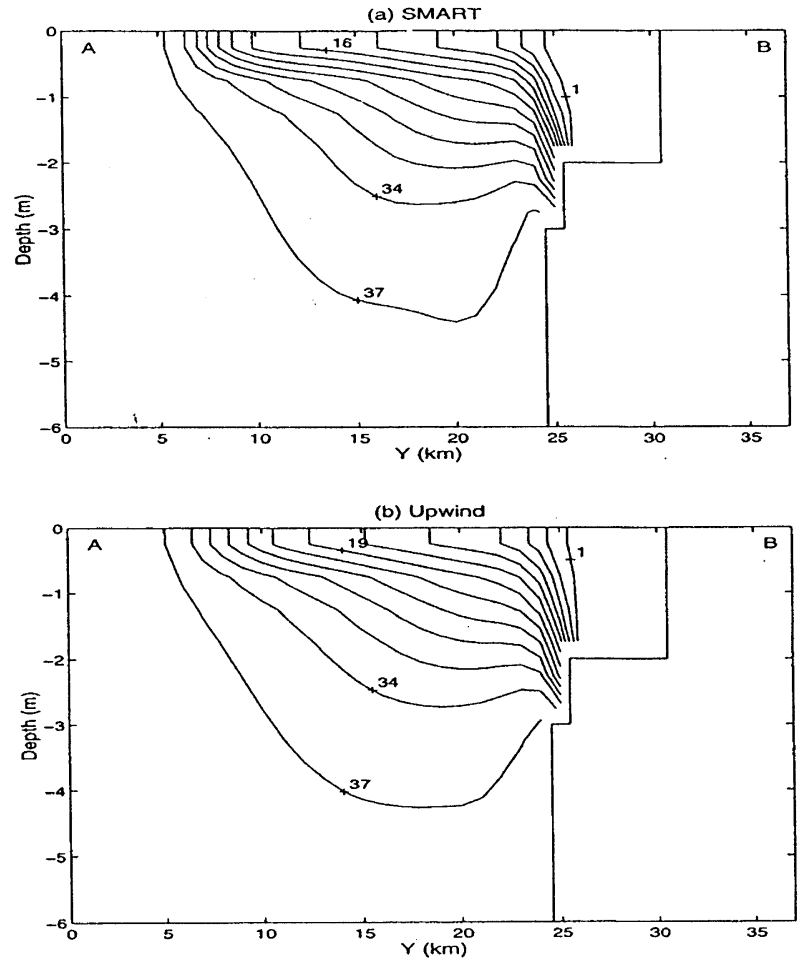

Fig. 4. Vertical view of the salinity field for both advection schemes along the south-north section $\mathrm{AB}$ as indicated in Figs. $2 \mathrm{~b}$ and 3. Isohalines are again plotted every $3 \mathrm{psu}$. The straight line right of the figure represents the sea bottom variability.

As numerical diffusion has strongly been damped, we may now interest confidently in the flow sensitivity to the turbulent parameters $D_{\mathrm{t} v 0}$ and $v_{\mathrm{t} v 0}$.

We noticed that whatever the way we used to increase $S c_{0}$, either by a decrease of $D_{\mathrm{t} v 0}$ or by an increase of $v_{\mathrm{t} v 0}$, the effects were qualitatively similar (Arnoux-Chiavassa, 1998). An increase of $S c_{0}$ from 0.6 to 1 results in a weak reduction of the plume velocity with a less mixed density structure. Downstream, a smoother transition from the anticyclonic vortex to the downstream coastal current is then observed.

Sensitivity on the surface velocity field due to the vertical mixing through the turbulent coefficients $v_{\mathrm{t} v 0}$ and $D_{\mathrm{t} v 0}$ for a fixed $S c_{0}$ is illustrated in Fig. 5. The decrease of the kinematic turbulent diffusion results in a flow acceleration and an increase of the inertial radius, the plume turning on its right further downstream. Transition from the near-field flow to the far-field flow is sharper, as noticed in the work of Chao and Boicourt (1986) and the coastal current becomes narrower. The effect on the salinity field is even less observable on horizontal surface gradients (Arnoux-Chiavassa, 1998).

The river flow rate and the densimetric Froude number $F r_{e}=\frac{U_{e}}{\sqrt{g \frac{\Delta \rho}{\rho_{r}} h_{e}}}$, where $\Delta \rho_{e}$ represents the density difference between fresh and saline water at the release point, are controlled by the values of the fresh water velocity $U_{e}$ and the water depth $h_{e}$ at the river mouth. A variation of the flow rate, induced by modifying either $U_{e}$ or $h_{e}$, influences both plume

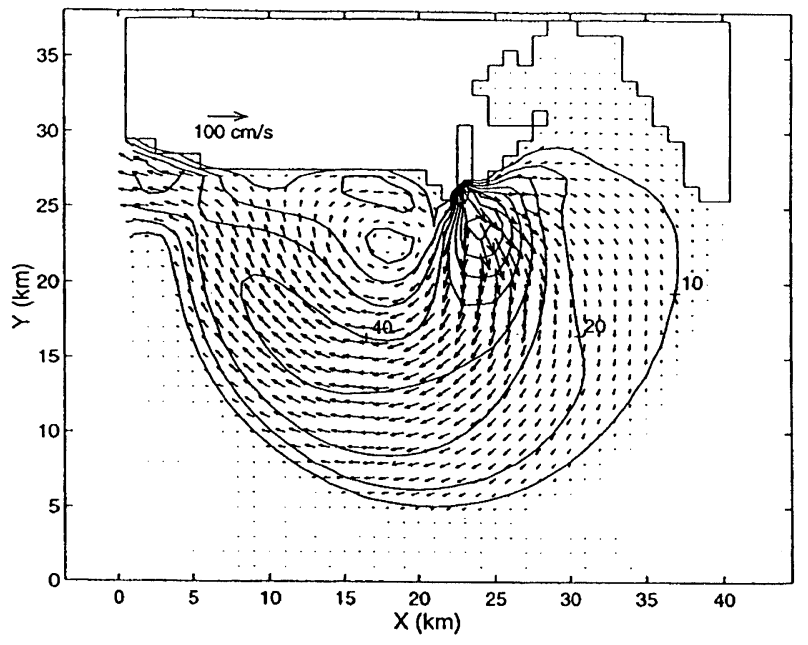

Fig. 5. As Fig. 2a except for the turbulent coefficients: $v_{\mathrm{t} v 0}=10^{-4} \mathrm{~m}^{2} \mathrm{~s}^{-1}$, $D_{\mathrm{t} v 0}=1.7 \times 10^{-4} \mathrm{~m}^{2} \mathrm{~s}^{-1}, S c_{0}=0.6$.

flow velocity and depth. On the other hand, for a given flow rate, an increase of the densimetric Froude number $\mathrm{Fr}_{e}$ sharpens the transitional zone between near-field flow and far-field flow, due to non-linear effects.

In situ surface currents measurements by VHF radars (Fig. 6) have been performed in the critical situation without wind associated to a calm sea (Broche et al., 1999). Indeed, as the VHF radars technique is to measure the Bragg waves velocity, the measurement points are sparse and sometimes polluted by echoes. However, the structure and extension of the plume flow is very comparable to the modeled flow (Fig. 2a).

Moreover, quasi-Lagrangian measurements of the surface velocity by using drifted buoys following the upper surface layer are compared to the computational results (Fig. 7) concerning a single trajectory but for two different values of $v_{\mathrm{t} v 0}$ varying from $10^{-4}$ to $6 \times 10^{-4}$.

The main specific pattern of river plumes in microtidal sea is related to the vertical structure of the flow, exhibiting a

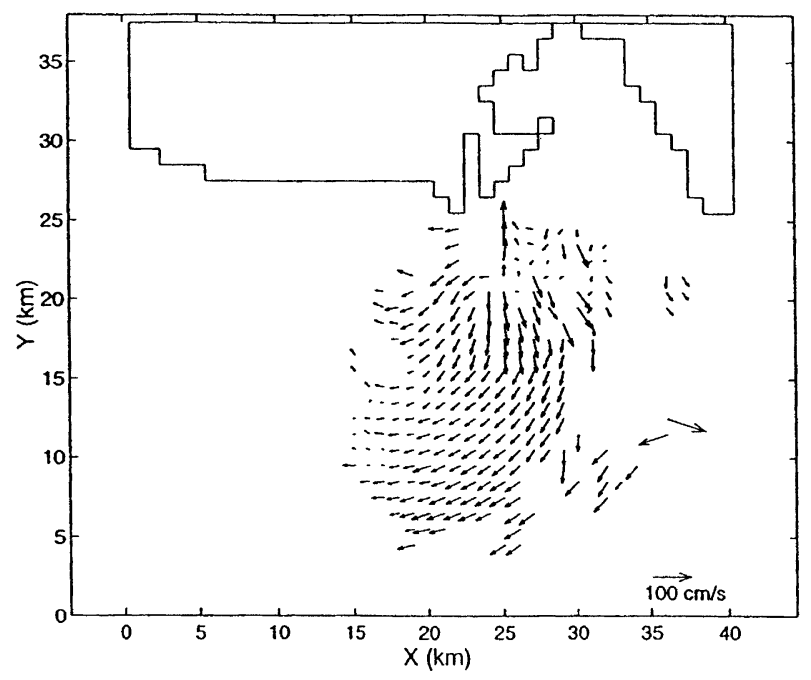

Fig. 6. Sea surface currents as measured by VHF radars on 21 November at 08:00 h. 


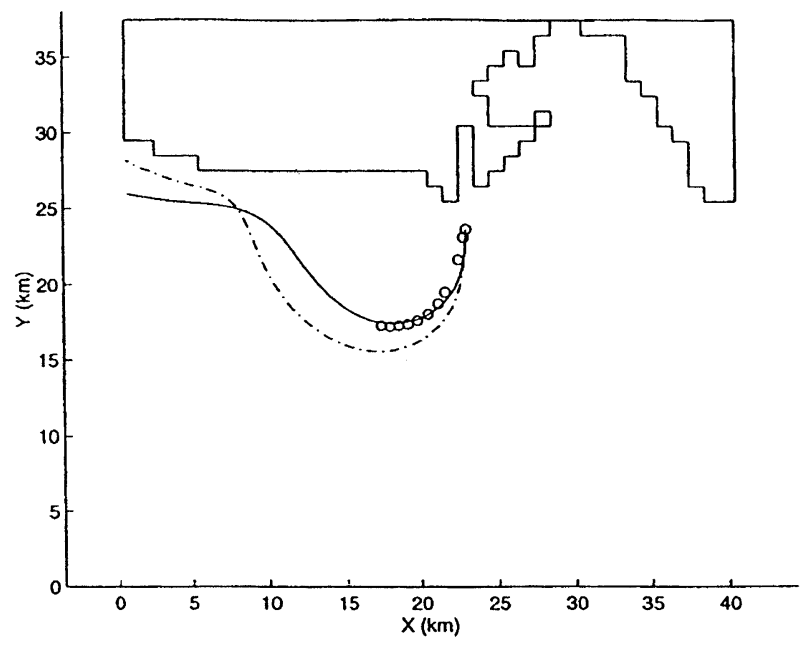

Fig. 7. Comparison between $(0)$ the in situ drifter tracking and the trajectory calculated from the computational results, $(-) v_{\mathrm{t} v 0}=6 \times 10^{-4} ;(-\cdot-\cdot-)$ $v_{\mathrm{t} v 0}=10^{-4}$.

clearly identified two layer structure (Garvine, 1987; Broche et al., 1999). Strong mixing of scalar fields in the freshwater upper layer has been observed on temperature and conductivity profiles. A number of computations (Arnoux-
Chiavassa, 1998) have shown that the turbulent diffusion coefficients have to be adjusted to recover such a behavior.

For this case without wind stress, as the Dittmar's hypothesis on the dissolved mineral matter distribution in open seas is not verified in the first CTD stations, quantitative reliable information on salinity cannot be deduced from conductivity measurements. Comparisons are, therefore, based on the temperature profiles in Fig. 8. Once more, the sensitivity to the turbulent momentum diffusivity coefficient $v_{\mathrm{t} v 0}$ is observed.

The in situ temperature profiles when following a drifted buoy in the river plume exhibit a very thin homogeneous surface layer whose water weakly mixes downstream with marine water. Nevertheless, a mixing operates as demonstrated by the warming of the surface water when going downstream.

Conductivity profiles not shown here exhibit the same structure, when distribution of salinity behaves the same way as temperature. The numerical simulation fails to represent the thickness of the homogeneous surface layer and the high degree of stratification of the interface; the computed interface is indeed not strong enough. On the other hand, the mixing rate between the river and the marine waters is cor-
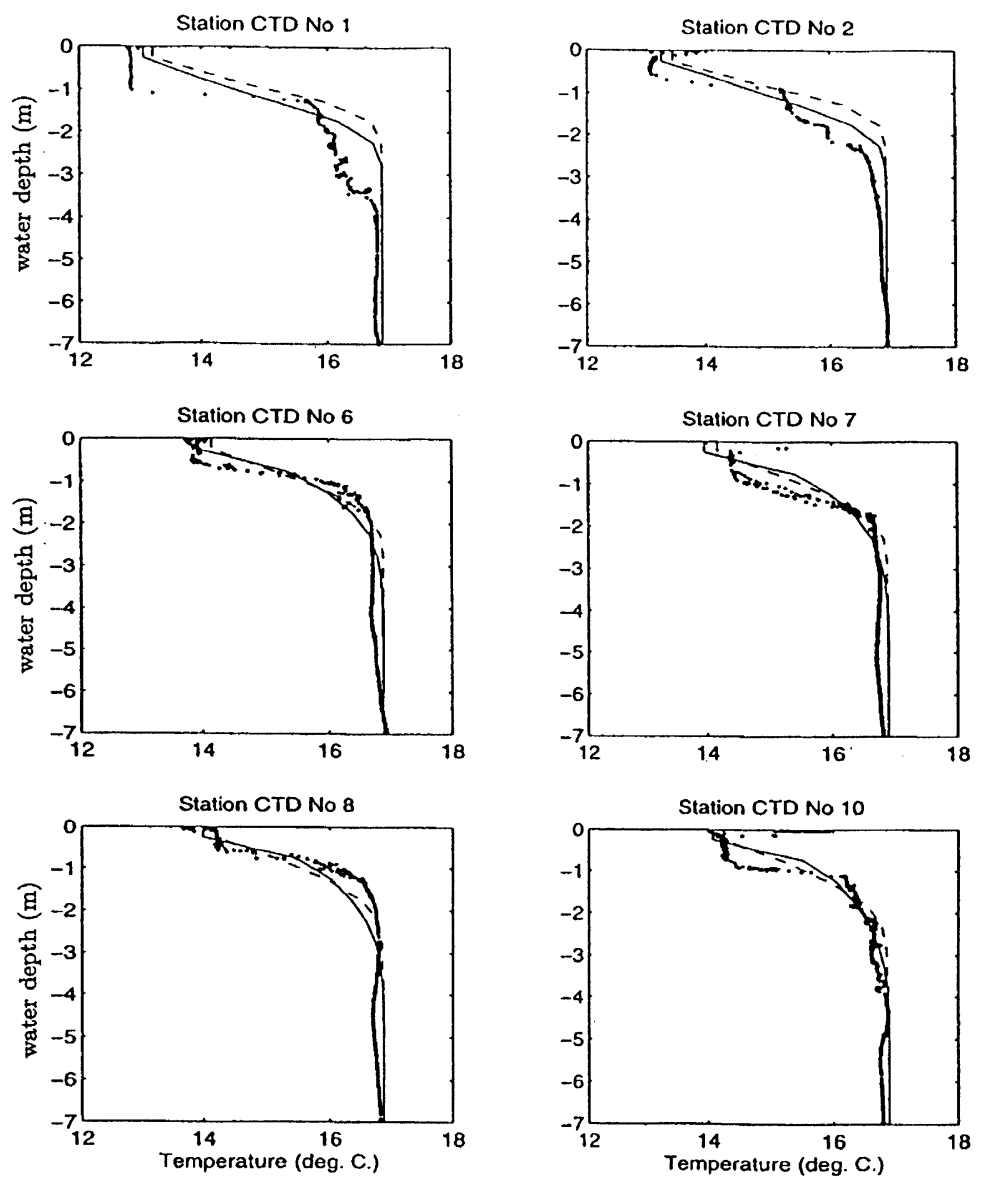

Fig. 8. Comparison between the in situ temperature profiles $(\bullet)$ and the computed temperature field at the same positions for the following coefficients $v_{\text {tv } 0}=6 \times$ $10^{-4} \mathrm{~m}^{2} \mathrm{~s}^{-1}(-) ; v_{\mathrm{t} v 0}=10^{-3} \mathrm{~m}^{2} \mathrm{~s}^{-1}(---) ; S c_{0}=0.6$, for six CTD stations. Locations of the CTD stations are indicated with circles in Fig. 7 and numbered from 1 to 11 (the first one is the closest to the river mouth). 


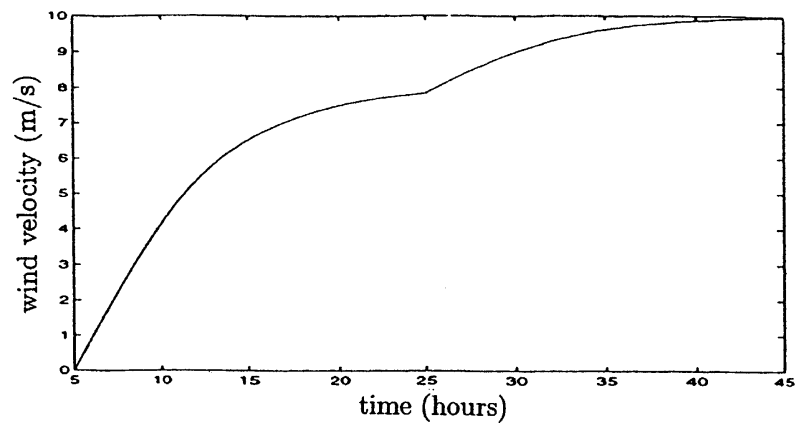

Fig. 9. Time evolution of the wind velocity forcing.

rectly reproduced; computed and observed surface temperatures are indeed very close to each other. Discrepancies are not due to a too large vertical resolution since simulations with a finer grid did not enlarge the thickness of the homogeneous surface layer. The weak point still remains the turbulence parameterization. Sophisticated models should reproduce a high mixing effect in the upper layer to induce its homogeneity and mixing with the warmer marine water, associated to a locally weak turbulence level to prevent from the smoothing of the strong interface separating both water masses.

\subsection{The wind-influenced plume circulation}

Another typical situation is the plume circulation influenced by a strong seaward (northerly) wind as encountered on 25th November 1994. The river discharge was of $2000 \mathrm{~m}^{3} \mathrm{~s}^{-1}$, slightly lower than in the previous case.

Surface velocity field measured by VHF radars are presented in Fig. 10. The northerly wind influence on the plume circulation is characterized by the frontal structure of the river plume, interacting with ambient upwelling flow.

Numerical results (Fig. 11) have been obtained by introducing the wind forcing after a spin up time of $5 \mathrm{~h}$ of the river plume circulation. In order to minimize inertial oscillations,

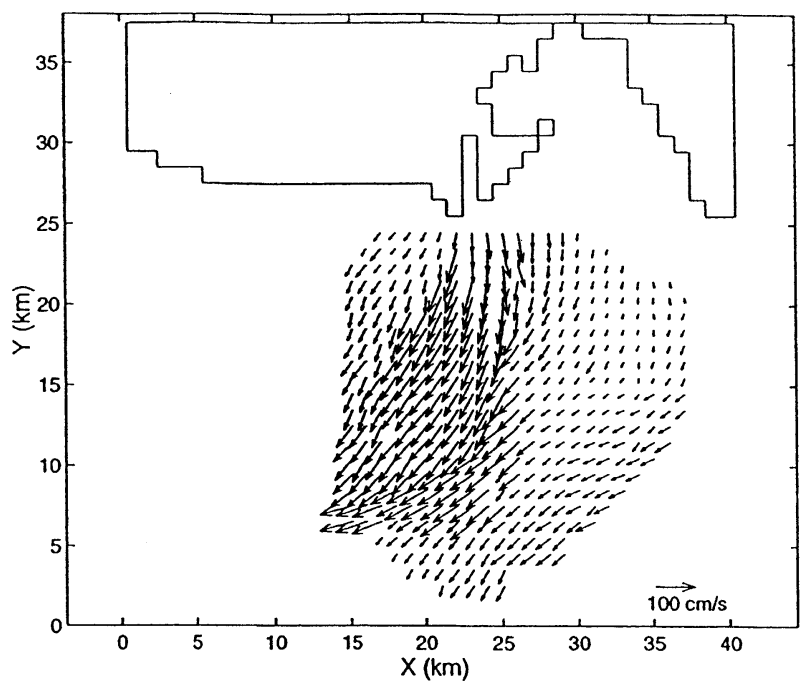

Fig. 10. Sea surface currents as measured by VHF radars on 25 November at 19:00 h.

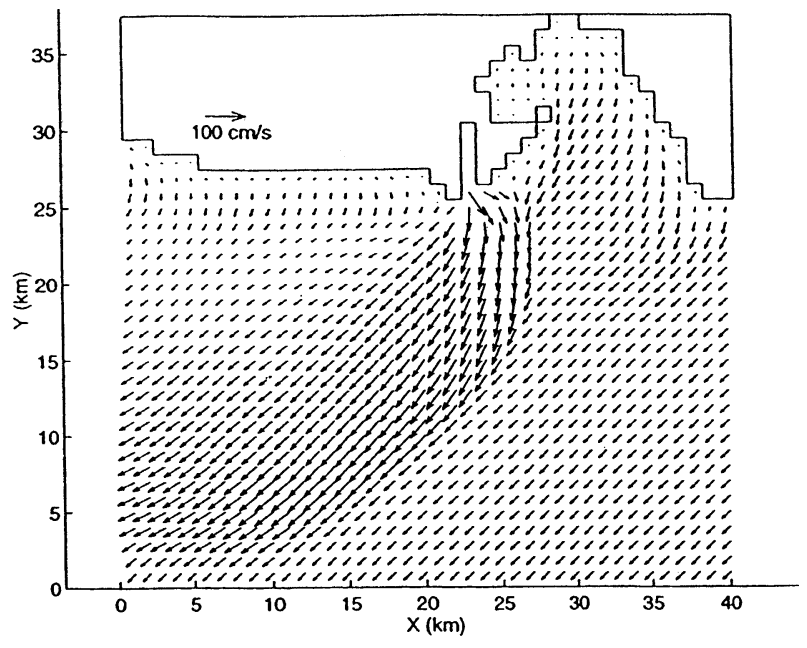

Fig. 11. Surface view of the velocity field obtained after $40 \mathrm{~h}$ of wind forcing using the SMART scheme and a value for the Schmidt number of the neutral state $\left(S c_{0}\right)$ of 0.6 .

the wind forcing velocity was prescribed by a tangential hyperbolic profile relaxed on a half inertial period (Fig. 9) up to $10 \mathrm{~m} \mathrm{~s}^{-1}$. As to introduce a link between the wind forcing and the turbulence level, the neutral viscosity coefficient $v_{\mathrm{t} v 0}$, which is a free parameter in the Munk and Anderson formulation (Eqs. [7] and [8]), takes the value for which the Ekman surface wind-induced current velocity $U_{\mathrm{c}}$ equals $3 \%$ of the wind velocity $U_{10}\left(U_{c}=\frac{\tau}{\rho \sqrt{f v_{t}}}=0.03 U_{10}\right)$. Two different values of the neutral Schmidt number have been compared: 0.6 and 1 .

In the surface layer, the plume is accelerated and swept southwestwards and the coastal current is no longer formed.

The position of the plume dynamic front upstream of the Ekman drift is recovered and the sharpness of this front is well reproduced by use of the Smart scheme (Fig. 11) but does not pertain when using the upwind scheme (not presented here).

This frontal region upstream of the Ekman drift is moreover marked by a strong downwelling effect due to the interaction between the river plume and ambient circulations. However, numerical results tend to slightly overestimate the plume width but to underestimate the velocity and the sharpness of the dynamic front downstream of the Ekman drift. Indeed, this latter is well marked on the radar maps and a few distinguishable when looking at the computed surface velocity field. A downwelling is also obtained in this region once more due to the interaction between the plume and ambient circulations, although it is weaker than the one existing on the other side of the plume. Finally, the wind-induced circulation outside the computed plume fits the description of a coastal upwelling in terms of free-surface elevation and vertical and horizontal velocity fields.

The in situ drifter tracking and the trajectories deduced from numerical simulations also agree well, whatever the value of the neutral Schmidt number (Fig. 12). 


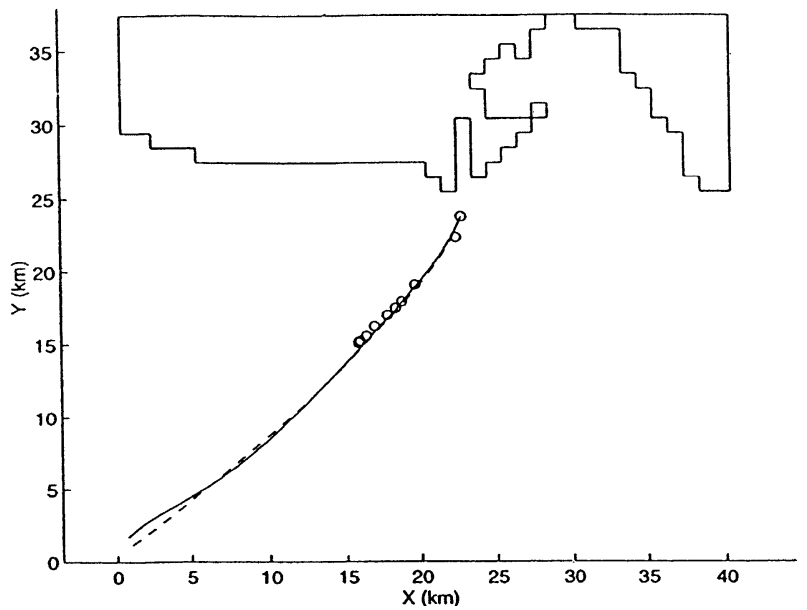

Fig. 12. Comparison between the in situ drifter tracking $(\bullet)$, labeled $1-11$ in the flow direction, and the trajectories calculated from the computational results for both values of the Schmidt number of the neutral state: $S c_{0}=0.6$ (一) and $S c_{0}=1(--)\left(S c_{0}\right)$.

The vertical density structure is strongly mixed by the wind stress providing a deeper plume layer. Fig. 13 displays salinity profiles calculated from in situ CTD data carried out at the series of stations indicated by circles in Fig. 12 together with computed profiles plotted at the same locations.
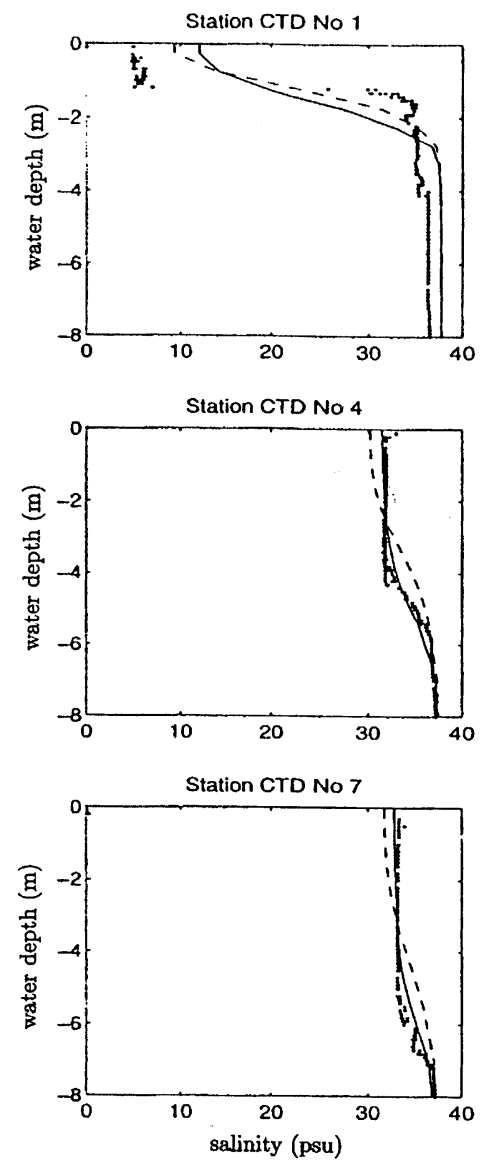

The high mixing rate between plume and marine waters allows in this case to deduce salinity values from conductivity measurements using the Fofonoff and Millard's (Fofonoff and Millard, 1983) algorithm.

The stratification characterizing the interface separating the homogeneous surface layer from the underlying sea waters is smoothed by the wind effects. The interface is now thicker and smoother than in the case without wind. Numerical results obtained with a neutral Schmidt number of 1 (dashed line) underestimate the wind-induced mass mixing. The surface salinity values indeed for each of these profiles lower than the measured one and the plume is also thinner. Improvements were obtained by using a neutral Schmidt number of 0.6 (solid line). Estimation of the surface salinity value then agrees well with the measured one. But numerical results still tend to underestimate the plume layer thickness, mostly at the end of the drifter course.

\section{Conclusion}

The Rhône river plume dynamics was computed for cases including or not wind effects by using either classical upwind scheme or total variation diminishing type scheme.
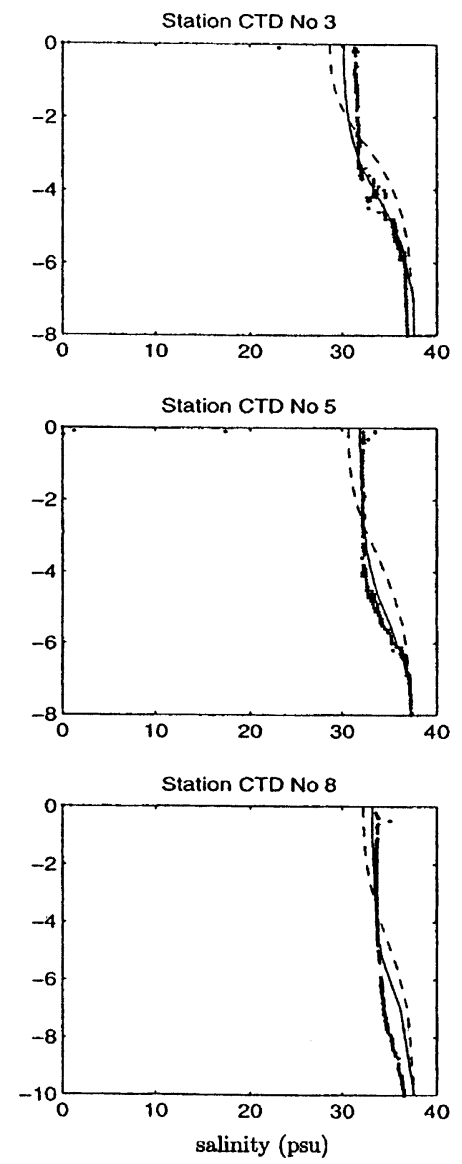

Fig. 13. Comparison between the salinity profiles deduced from in situ data $(\bullet)$ and the computed salinity field at the same positions for four CTD stations and for both values of the neutral Schmidt number: $0.6(-)$ and $1(--)$. 
The use of a higher-order advection scheme (the SMART scheme, Gaskell and Lau, 1988) for both dynamical and scalar fields, even with $20 \%$ cpu over-cost, has shown to significantly damp the numerical diffusion, allowing a good representation of the haline and dynamic fronts. In such a way, the effects of control parameters like turbulent coefficients or inflow parameters on the plume dynamics were quantitatively estimated. In particular, the non-linear effects of the turbulent mixing level on the width of the coastal current, or the link between the inflow densimetric Froude number and the sharpness of the transition from the near-field flow to the far-field flow in the case without wind were evidenced.

For the river flow induced plume circulation, the comparison of the numerical results with in situ data has shown a quite good agreement on the surface velocity field. However, the observed two-layers structure of the vertical density profile is not fully recovered due to the limitation of the MunkAnderson mixing model for very high Richardson numbers. Recent field measurements (Forget et al., this issue) have shown that different turbulent mixing processes act for salinity and momentum fields inducing a quasi two-layers structure for the scalars in combination with a smoother sheared interface for the velocity fields. Such a behavior combined with an asymmetric flux of salinity is expected to be induced by breaking internal waves for high Richardson numbers. For the wind dominated plume circulation, the neutral turbulent viscosity coefficient value was chosen in order to insure a good balance between the wind strength and the mixing level. For this seaward wind case, a good agreement was obtained with the observed surface velocity fields, especially concerning the dynamic front of the plume upstream of the Ekman drift, as well as on the vertical density structure for a neutral Schmidt number of 0.6. Nevertheless, the modeling tends to slightly overestimate the width of the plume flow and to underestimate the velocity field and the mass mixing. Only in this case, the turbulent mixing could be improved by using a second order turbulence closure model (Luyten et al., 1996; Burchard et al., 1998; Verdier-Bonnet et al., 1999). Indeed, a non-uniform surface turbulent field may lead to a more accurate surface velocity field inside and outside of the plume flow. Moreover, the use of such a turbulence model allows to introduce wave effects depending on the fetch in the surface boundary conditions (Craig and Banner, 1994). Breaking wave effects on the turbulent mixing in a river plume were also investigated by Xing and Davies (1999).

\section{Acknowledgements}

This research was carried out within the framework of the scientific program Pnec (Programme National d'Environnement Côtier, Atelier Golfe du Lion). Its financial support is acknowledged.

\section{References}

Arakawa, A., Lamb, V.R., 1977. Computational design of the basic dynamical processes of the UCLA general circulation model. Methods Comput. Phys. 17, 173-265.

Arnoux-Chiavassa, S., 1998. Modélisation d'écoulements côtiers stratifiés présentant des fronts: application au panache du Rhône. Thèse de l'Université de Toulon et du Var.

Arnoux-Chiavassa, S., Baeckeroot, A., Baghdadi, N., Broche, P., Devenon, J.L., Forget, P., Gagelli, J., De Maistre, J.C., Ouillon, S., Rey, V., Rougier, G., 1995. Field campaign off the Rhône river mouth. Proceedings of the Second International Conference on the Mediterranean Coastal Environment. Tarragona, Spain.

Arnoux-Chiavassa, S., Rey, V., Fraunié, P., 1999. Modelling of suspended matter fluxes off the Rhône river mouth. J. Coastal Res. 15 (1), 61-73.

Beardsley, R.C., Hart, J., 1978. A simple theoretical model for the flow of an estuary onto a continental shelf. J. Geophys. Res. 83, 873-883.

Broche, P., Devenon, J.L., Forget, P., de Maistre, J.C., Naudin, J.J., Cauwet, G., 1998. Experimental study of the Rhône River plume. Part I: physics and dynamics. Oceanol. Acta 21, 725-738.

Brooks, D.A., 1994. A model study of the buoyancy-driven circulation in the Gulf of Maine. J. Phys. Oceanogr. 24, 2387-2412.

Burchard, H., Petersen, O., Rippeth, T.P., 1998. Comparing the performance of the Mellor-Yamada and the $\varepsilon$ two-equation turbulence models. J. Geophys. Res. 103 (C5), 10543-10554.

Chao, S.-Y., 1988a. Wind-driven motion of estuarine plumes. J. Phys. Oceanogr. 18, 1144-1166.

Chao, S.-Y., 1988b. River-forced estuarine plumes. J. Phys. Oceanogr. 18, $72-88$.

Chao, S.-Y., Boicourt, W.C., 1986. Onset of estuarine plumes. J. Phys. Oceanogr. 16, 2137-2149.

Craig, P.D., Banner, M.L., 1994. Modeling wave-enhanced turbulence in the ocean surface layer. J. Phys. Oceanogr. 24, 2546-2559.

Davies, A.M., Xing, J., 1999. Sensitivity of plume dynamics to parameterisation of vertical mixing. Int. J. Num. Fluids 30, 357-405.

Estournel, C., Kondrachoff, V., Marsaleix, P., Vehil, R., 1997. The plume of the Rhone: numerical simulation and remote sensing. Contin. Shelf Res. 17, 899-924.

Fofonoff, N.P., Millard, R.C., 1983. Algorithms for computation of fundamental properties of seawater. UNESCO technical papers in marine science, 44. UNESCO.

Galperin, B., Kantha, L.H., Hassid, S., Rosati, A., 1988. A quasi-equilibrium turbulent energy model for geophysical flows. J. Atmos. Sci. 45, 55-62.

Garvine, R.W., 1977. Observations of the motion field of the Connecticut river plume. J. Geophys. Res. 83, 441-454.

Garvine, R.W., 1982. A steady state model for buoyant surface plume hydrodynamics in coastal waters. Tellus 34, 293-306.

Garvine, R.W., 1984. Radial spreading of buoyant surface plumes in coastal waters. J. Geophys. Res. 89, 1989-1996.

Garvine, R.W., 1987. Estuary plumes and fronts in shelf waters: a layer model. J. Phys. Oceanogr. 17, 1877-1896.

Gaskell, P.H., Lau, A.K.C., 1988. Curvature-compensated convective transport: SMART, a new boundedness-preserving transport algorithm. Int. J. Num. Methods Fluids 8, 617-641.

Ibanez, C., Pont, D., Prat, N., 1997. Characterization of the Ebro, Rhône estuaries: a basis for defining and classifying salt-wedge estuaries. Limnol. Oceanogr. 42, 89-101.

Ikeda, M., 1984. Coastal flows driven by a local density flux. J. Geophys. Res. 89, 8008-8016.

Ivey, G.N., Imberger, J., 1991. On the nature of turbulence in a stratified fluid. Part I: the energetics of mixing. J. Phys. Oceanogr. 21, 650-658.

James, I.D., 1996. Advection schemes for shelf sea models. J. Mar. Syst. 8, 237-254.

Kao, T.W., Park, C., Pao, H.-P., 1977. Buoyant surface discharge and small-scale oceanic fronts: a numerical study. J. Geophys. Res. 82 (12), 1747-1752. 
Kourafalou, V.H., Lee, T.N., Oey, L.-Y., Wang, J.D., 1996. The fate of river discharge on the continental shelf. 2. Transport of coastal low-salinity waters under realistic wind and tidal forcing. J. Geophys. Res. 101, $3435-3455$.

Launder, B.E., 1978. Heat and mass transport. In: Bradshaw, P. (Ed.), Turbulence. Springer, Berlin.

Leonard, B.P., 1979. A stable and accurate convective modelling procedure based on quadratic upstream interpolation. Comput. Methods Appl. Mech. Eng. 19, 59-98.

Leonard, B.P., Drummond, J.E., 1995. Why you should not use 'hybrid', 'power-law' or related exponential schemes for convective modelling - there are much better alternatives. Int. J. Num. Methods Fluids 20, 421-442.

Leonard, B.P., Mokhtari, S., 1990. Beyond first-order upwinding: the ULTRA-SHARP alternative for non-oscillatory steady-state simulation of convection. Int. J. Num. Methods Fluids 30, 729-766.

Lin, B., Falconer, R.A., 1996. Numerical modelling of three-dimensional suspended sediment for estuarine and coastal waters. J. Hydraulic Res. 34 (4), 435-456.

Linden, L.F., 1980. Mixing across a density interface produced by grid turbulence. J. Fluid Mech. 100, 691-703.

Luyten, P.J., Deleersnijder, E., Ozer, J., Ruddick, K.G., 1996. Presentation of a family of turbulence closure models for stratified shallow water flows and preliminary applications to the Rhine outflow region. Contin. Shelf Res. 16, 101-130.

Marsaleix, P., Estournel, C., Kondrachoff, V., Vehil, R., 1998. A numerical study of the formation of the Rhône river plume. J. Mar. Syst. 14, 99-115.

Mellor, G., Yamada, T., 1982. Development of a turbulence closure model for geophysical fluid problems. Rev. Geophys. Space Phys. 20, 851-875.

Millot, C., 1990. The Gulf of Lions' hydrodynamics. Contin. Shelf Res. 10, 885-894.

Munk, W.H., Anderson, E.A., 1948. Notes on a theory of the thermocline. J. Mar. Res. 7, 276-295.

O'Donnell, J., 1986. A numerical model of the dynamics of buoyant discharges. Ph.D. Dissertation. University of Delaware, pp. 182.

O'Donnell, J., 1990. The formation and fate of a river plume: a numerical model. J. Phys. Oceanogr. 20, 551-569.

Oey, L.-Y., Mellor, G.L., 1993. Subtidal variability of estuarine outflow, plume, and coastal current: a model study. J. Phys. Oceanogr. 23, $164-171$.
Ouahsine, A., Smaoui, H., 1999. Flux-limiter schemes for oceanic tracers: application to the English Channel tidal model. Comput. Methods Appl. Mech. Eng. 179, 307-325.

Rodi, W., 1984. Turbulence models and their application in hydraulics. Int. Assoc. Hydraulic Res. Monograph Series, Delft.

Roe, P.L., 1985. Some contribution to the modelling of discontinuous flows. In: Engquist, E., et al. (Eds.), Am. Math. Society, pp. 183 Large Scale Computations in Fluid Mechanics, Part 2 (Lectures in Applied Mathematics 22).

Ruddick, K., 1995. Modelling of coastal processes influenced by the freshwater discharge of the Rhine Thése de doctorat de l'Université de Liége.

Ruddick, R.G., Deleersnijder, E., Luyten, P.J., Ozer, J., 1995. Haline stratification in the Rhine-Meuse freshwater plume: a three-dimensional model sensitivity analysis. Contin. Shelf Res. 15 (13), 1597-1630.

Simpson, J.H., 1997. Physical processes in the ROFI regime. J. Mar. Syst. $12,3-15$.

Stern, M.E., Whitehead, J.A., Hua, B.-L., 1982. The intrusion of a density current along the coast of a rotating fluid. J. Fluid Mech. 123, 237-265.

Sweby, P.K., 1984. High resolution schemes using flux limiters for hyperbolic conservation laws. SIAM J. Num. Anal. 21, 995-1011.

Tomidokoro, G., 1984. Basic studies on the hydraulic characteristics of the wind-induced currents and pollutant dispersion in closed shallow water basin. Kyoto University, Japan Doctoral dissertation.

Varonos, A., Bergeles, G., 1998. Development and assessment of a variableorder non-oscillatory scheme for convection term discretization. Int. J. Num. Methods Fluids 26, 1-16.

Verdier-Bonnet, C., Angot, P., Fraunié, P., Coantic, M., 1999. Three dimensional modelling of coastal circulations with different kappa- $\epsilon$ closures. J. Mar. Syst. 21 (1-4), 321-339.

Vickers, D., Mahrt, L., 1997. Fetch limited drag coefficients. Bound. Lay. Met. 85, 53-79.

Wang, D.P., 1984. Mutual intrusion of a gravity current and density front formation. J. Phys. Oceanogr. 14, 1191-1199.

Weaver, A.J., Hsieh, W.W., 1987. The influence of buoyancy flux from estuaries on continental shelf circulation. J. Phys. Oceanogr. 17, 21272140.

Wurtele, M.G., Paegle, J., Sielecki, A., 1971. The use of open boundary conditions with the storm surge equations. Mon. Weather Rev. 99 (6), 537-544.

Xing, J., Davies, A.M., 1999. The effect of wind direction and mixing upon the spreading of buoyant plume in a non-tidal regime. Contin. Shelf Res. $19,1437-1483$. 